\title{
Imploring the Gap Between Top Ranked Global Universities and Jiangsu University \& the University of Nairobi with the Aim of De-gaping Through Addressing These Disparities
}

\author{
Joseph Muiruri Thige*, Li Hongbo, Ssali Max William, Duncan Omenda Hongo, \\ Flavian Athiambo Othiambo, Consolata Wairimu Nderitu, Joice Meshi Foku
}

School of Management, Management Science and Engineering, Jiangsu University, Zhenjiang, China

Email address:

josephthige@gmail.com (J. M. Thige), lhb@ujs.edu.cn (Li Hongbo)

*Corresponding author

To cite this article:

Joseph Muiruri Thige, Li Hongbo, Ssali Max William, Duncan Omenda Hongo, Flavian Athiambo Othiambo, Consolata Wairimu Nderitu, Joice Meshi Foku. Imploring the Gap Between Top Ranked Global Universities and Jiangsu University \& the University of Nairobi with the Aim of De-gaping Through Addressing These Disparities. American Journal of Management Science and Engineering.

Vol. 6, No. 4, 2021, pp. 95-102. doi: 10.11648/j.ajmse.20210604.13

Received: July 4, 2021; Accepted: July 22, 2021; Published: August 5, 2021

\begin{abstract}
Higher education institutions (HEIs) employ varying parameters to increase their assessment and consideration as institutions of choice for learners and competitiveness in comparison to other institutions offering similar content output. All institutions of higher Education gear towards growing their capacity in both qualitative and quantitative domains as they seek to change positively the society within and without the HEIs jurisdiction. The growing need for visibility and demand for higher education has left many higher education institutions with a mirage of challenges on how to improve access while maintaining quality. This research focused broadly on; ranking determinants and development of Higher Education Institutions (HEIs), and the impact and inter-relational effects the determinants of academic quality postulates on academic quality development, while comparatively critiquing the academic dynamics for University of Nairobi (UON) \& Jiangsu University (UJS). Specifically, and regarding the ranking systems, academic quality of UJS and UON, certain contemporary study design guided current study. The depth, quality and reliability of ranking determinants as the nature of HEIs internal quality assessment and external visibility is investigated as it largely underscores on the nature and weight of ranking variances implored by the various ranking systems of HEIs a midst their developmental antecedents under higher academia to underscore the comparative significance, directions and (inter)-correlational characteristics amid UJS \& UON's contemporary higher education variances in their process of academic developmental antecedents and process. The research then delves at the impact of key parameters (teaching, research, attitude, performance and internationalization) on changing the academic quality of UON and UJS and on a comparative domain, finally the study tackles the effects of inter-relational associations of key parameters to the academic quality at both vertical and cross-section analogy in a bid to address their relevance and effects of academic quality and collaboration amid UON and UJS. The methodological underpinning implied to actuate the objectives is mixed in approach. Its qualitatively intensive where the quality and reliability of ranking systems is delved from a review process of the relevant literature concerning HEI's, while an intensive-descriptive to qualitative review technique is implied resulting to a critical analysis of relevant literature. The study compares and contrasts the ranking variances for UON \& UJS higher academia being quantitative intensive and integrated in approach while using primary data to quantify the fact that there exist variances and impacts amid the higher academia of UON \& UJS.
\end{abstract}

Keywords: Research Methodology, Higher Education, Qualitative, Quantitative, Variances, Comparative Ranking 


\section{Introduction}

It's important to study these ranking systems in depth given the impact and visibility this brings to higher educational institutions globally. This study seeks to compare the wide academic development variances referred to as the (gap) in variables factored in cross comparison of ARWU, WRWU, THE, QS, and U.S.News.com 's HEI's ranking systems.

The study investigates the nature of ranking systems in categorizing the HEIs' that are gearing towards bettering their academic quality, and the parameter variances used by ranking houses in qualifying the HEIs and this is the concern expected to be actuated using methodological technique that is mixed in approach. Its qualitatively intensive where the quality and reliability of ranking systems is delved from a review process of the relevant literature concerning HEI's while the an intensive-descriptive to qualitative review technique resulting to a critical analysis of relevant literature.

The study quantitatively expects to delve the impacts, effects ad inter-relational effects of teaching, research, internationalization, learner attitude and performance on academic quality of UJS and UON. This is the integrated concern which aims to compare and contrast the ranking variances for UON/UJS higher academia as quantitative intensive and integrated in approach while using primary data to quantify the fact that there exist variances amid the higher academia of UON and UJS. It works out the variances of the two universities (UON and UJS) using rich methodological techniques and approaches relevant to the data demands; that is, the ordinal regression, independent T-test and correlation matrix that were important for comparative analysis.

Operations is also integrated using the structural regressions on different dataset to find and assert the impacts, correlations and other inter-relational effects of key parameters of academic quality to the growth and development of quality academia for UJS and UON. It employs the SEM model that best and structurally defines the causality path, effect and impact path of the key parameters on academic quality. Specific operations are detailed in the respective section.

The research design incorporating the methodology of the study encompassed both qualitative and quantitative research techniques with the research generally exploring a contingent of data sources (refer to Table 1) and their effect on academic achievement, the assessment provides insight on how universities compare globally in the University Rankings. Ranking systems began popping up all over the world in between 2003 and now, usually shortly after the introduction of or a rapid rise in tuition fees. Wherever rankings have appeared, they have been met with a mixture of public enthusiasm and institutional unease as reviewed by Altbach in university rankings $\mathrm{Pg} 26-31$ [1] ${ }^{1}$

For ease of grip, this study enshrining the methodology which regards the data and analytics of the study is therefore discussed under its sub parts. That is, the ranking parameters

1 Altbach, P. G. (2012). The globalization of college and university rankings. Change: The Magazine of Higher Learning, 44 (1), 26-31. of the study, design of the research, the data sources and methods of data collection.

\section{Methodology Parameters of Study}

The study implored a number of parameters mainly explaining the Gap between UJS \& UON and Top ranked Global Universities and are banked upon due to the fact that they provide grounds for UJS \& UON to set their own pace through benchmarking of their academic infrastructure against these global pace setting institutions together with underlined assessment with the aim of de-gaping through addressing the disparities according to 1 Tosun, A Performance Assessment Model pg. 420-431 [2] $]^{2}$. In this line, below are some of selected ranking systems and associated parameters; that is WRWU, THE, QS, ARWU, U.S.News.com World Report as contained in the academic rankings' web pages $[3]^{3}$

Specifically, and regarding the ranking systems and/or parameter, academic quality of UJS and UON, certain contemporary study objectives guided current study which was operated on qualitative and quantitative approach. With the first aim, the depth, quality and reliability of ranking determinants as the nature of HEIs internal quality assessment and external visibility is investigated as the second objective largely underscored on the nature and weight of ranking variances implored by the various ranking systems of HEIs a midst their developmental antecedents under higher academia. The third and fourth objectives are deeply integrated and largely quantitative in order to best underscore the comparative significance, directions and (inter)-correlational characteristics amid UJS \& UON's contemporary higher education variances in their process of academic developmental antecedents and process.

a) U.S.News.com World Report (2014)

The system of ranking postulates the specific ranking parameters as following based on different ranking systems; The U.S.News.com has 12 variables and weight (that is; Global research - 12.5\%, Regional Research - 12.5\%, Publications - 10\%, Books - 2.50\%, Conferences 2.50\%, Normalized citation $-10 \%$, Total citations $-7.50 \%$, Number of Publications $-12.50 \%$, Percentage of total $-10 \%$, International $10 \%$, Number of PHDs awarded $-5 \%$ and Number of PHDs awarded per academic year $-5 \%$ ),

b) THE's (2004)

These system of ranking established in 2004 has its variables and weights forming the qualitative grounds for THE's assessments included; The variables include; Teaching (30\%), Research quality (30\%), Total Citations (32.5\%), Industrial income $(2.5 \%)$ and International outlook (5\%).

c) QS (2004)

\footnotetext{
2 Tosun, H. (2019). A Performance Assessment Model Recommended for Higher Education System in Turkey and a Case Study. Psychology Research, October, 9 (10), 420-431.

3 THE (www.timeshighereducation.com/(QS (www.topuniversities.com) WRWU www.webometrics.info/en ARWU (www.arwu.org) and, U.S.news.com http://www.u.s.news.com/ 2010-2019.
} 
The QS system of ranking also established in the year 2004 has its parameters of ranking comprising of; Research quality: $40 \%$; Graduate employability: $10 \%$; Teaching quality: Total of $40 \%$; International outlook: $5 \%$ and $5 \%$ respectively giving it a total $10 \%$.

d) ARWU (2003)

The ARWU system of ranking established in 2003 comprises of the following variables; Research output- $20 \%$,
Citation impact- 20\%, Total citations- 20\%, Publications- 20\%, Per capita Performance- 10 and Quality of education- $10 \%$.

e) WRWU (2004)

Regards of WRWU established in the year 2004 as well, has the following parameters as of concern; Presence- 5\%, Visibility- $\quad 50 \%$, Transparency/openness- $10 \%$ and Excellence/scholar- $35 \%$.

Table 1. Comparative analysis global University: Webometrics Ranking of UJS \& UON.

\begin{tabular}{llllllll}
\hline & Country Ranking & Presence & Impact/Visibility Rank & Openness Rank & Excellent Rank & Continent Rank & World Rank \\
\hline UON Jan 2019 & 1 & 261 & 839 & 1217 & 1580 & 9 \\
UON July 2019 & 1 & 578 & 1028 & 881 & 1607 & 9 \\
UJS Jan 2019 & 70 & 2084 & 1246 & 1493 & 500 & 1031 \\
UJS July 2019 & 62 & 1204 & 1177 & 1318 & 461 & 127 & 112 \\
\hline
\end{tabular}

Source: http://www.webometrics.info/en's

Table 1 forms a comparative assessment of UJS \& UON globally. Based on four variances namely Impact, Openness, Excellence and presence; each of the two HEIs perform well nationally and regionally ranking $1^{\text {st }}$ nationally for UON and among the top 70 in the two rankings for 2019 cumulation. Because both HEIs are in different regions, the only way to aggregate them is to look at the global placement which places UON 188 places lower than UJS in January 2019 and places UON 379 places lower than UJS in 2019 July aggregation. this shows a significant rise within 2019 for UJS and a drop of UON on the same period under review. The reason for the current ranking of both UON \& UJS by WRWU is based on the variances and weights given to those variances. while presence is allocated a weight of $5 \%$, Visibility or impact is allocated $50 \%$ which is the highest weight for the four variances given and almost becomes a determinant factor followed by Excellence or Scholar variance which is given a weight of $35 \%$. Transparency or openness is only given an aggregation of $! 0 \%$ which does not majorly affect the overall ranking of a HEI. Comparing the two HEIs on the Four variances therefore shows how this study came up with the assessment of the gap.

Table 2. UON-Webometrics Ranking over a 10-year period.

\begin{tabular}{|c|c|c|c|c|c|c|c|c|c|c|c|}
\hline & Jan-09 & Jul-09 & Jan-10 & Jul-10 & Jan-11 & Jul-11 & Jan-12 & Jul-12 & Jan-13 & Jul-13 & Jan-14 \\
\hline Continental Rank & 29 & 24 & 28 & 26 & 27 & 26 & 17 & 14 & 12 & 9 & 9 \\
\hline World Rank & 4046 & 4467 & 3897 & 3190 & 3136 & 2452 & 1367 & 1435 & 1326 & 1624 & 1167 \\
\hline Presence/Size & 3069 & 2490 & 3136 & 1905 & 1976 & 2045 & 631 & 839 & 1528 & 619 & 1828 \\
\hline Visibility/Openness Rank & 5413 & 7001 & 4679 & 4119 & 4335 & 4215 & 1794 & 2010 & 2981 & 2883 & 1898 \\
\hline Rich files/Impact Rank & 3851 & 4327 & 4363 & 3447 & 3310 & 4942 & 2761 & 4057 & 950 & 1119 & 774 \\
\hline Excellent Rank/ Scholarly work & 3839 & 3711 & 4104 & 3809 & 4382 & 1706 & 1724 & 1342 & 1346 & 1323 & 1329 \\
\hline
\end{tabular}

Table 2. Continued.

\begin{tabular}{|c|c|c|c|c|c|c|c|c|c|c|}
\hline & Jul-14 & Jan-15 & Jul-15 & Jan-16 & Jul-16 & Jan-17 & Jul-17 & Jan-18 & Jul-18 & Jan-19 \\
\hline Continental Rank & 10 & 8 & 8 & 7 & 11 & 8 & 7 & 10 & 9 & 8 \\
\hline World Rank & 907 & 834 & 841 & 789 & 1285 & 890 & 796 & 1131 & 1008 & 971 \\
\hline Presence/Size & 1109 & 798 & 1256 & 1501 & 906 & 1834 & 918 & 734 & 1180 & 692 \\
\hline Visibility/Openness Rank & 2225 & 194 & 1789 & 2041 & 2090 & 1489 & 833 & 928 & 1489 & 970 \\
\hline Rich files/Impact Rank & 44 & 520 & 721 & 3197 & 2281 & 496 & 2355 & 839 & 547 & 743 \\
\hline Excellent Rank/ Scholarly work & 1403 & 1402 & 1386 & 1822 & 1247 & 1421 & 1383 & 1398 & 1269 & 1488 \\
\hline
\end{tabular}

Source: http://www.webometrics.info/en's

Table 2 depicts a period of 10 years WRWU aggregation of UON based on bi-annual assessment using four variances and the weights allocated with 5\% being the lowest and 50\% being the highest on presence and visibility respectively. In this period of higher education ranking and basing on WRWU rank data; the period seems to depict UON as to have the highest level of aggregation advantage nationally based on its institutional and academic setup.

The university ranks best in Kenya in all years reviewed while it improved exponentially in the first half of the period under review both regionally and globally from position $29^{\text {th }}$ to position $9^{\text {th }}$ and from position $4046^{\text {th }}$ to position $1624^{\text {th }}$ respectively. in the second half of the period under review, the university fluctuates from position $9^{\text {th }}$ to position $8^{\text {th }}$ regionally with $11^{\text {th }}$ being their least performance and $7^{\text {th }}$ being the best. Globally, the trend in the first half of the period under review also shows an improved ranking from position $4046^{\text {th }}$ in Jan 2009 to position $1624^{\text {th }}$ in July 2013 giving an aggregate of $2835^{\text {th }}$ for the five years period under review. The second period under review shows a fluctuation in global ranking with the least ranked aggregate being $1167^{\text {th }}$ and $789^{\text {th }}$ being the best performed aggregation. this gives a second average aggregate 
of $978^{\text {th }}$ for the five years under review.

This downward trend in the university ranking may inevitably be de-linked to a number of factors which might include the academic and numerical data as contained in table 5 with the most impactful according to this study being internationalization where UON has $1 \%$ of its entire student population being foreign and student to teacher ratio being 30 to 1 which might affect quality supervision and timely assessment of the students' academic growth. Other factors might include five years delay in data release based on its annual report publication thus limiting access to the ranking systems who use this data to make an analysis and assessment for ranking through publications, citations, industry and income and technological advancement while also having a conglomeration diversity based on ethnicity, of both students and faculty members, as a result, they produced the highest numbers of high impact papers cited in the period 2009-2019. As per the specific statistics and regional demographics created by the citations, impacts and ranking, this could be grounds for future researchers to explore and suggest what Higher education institutions can do to encourage inter institutional citations.

Table 3. UJS\& UON's academic outlook: THE ranking.

\begin{tabular}{|c|c|c|c|c|c|c|}
\hline & Teaching & Research & Citations & Industry Income & International Outlook & Overall \\
\hline UJS & 13.7 & 10.4 & 16.8 & 35.1 & 46.8 & \multirow[t]{2}{*}{-} \\
\hline UON & 19.4 & 11.4 & 26.9 & 56.7 & 35.1 & \\
\hline
\end{tabular}

The researcher selected this ranking system because of the depth and breadth of its reach, the ranking system embraces all academic institutions offering all post high school qualifications ranked both UJS \& UON nationally, continentally and globally. whereas UON ranked as the top university in Kenya for all years assessed by WRWU, UJS ranked 72 in the People's Republic of China in national ranking. UON also did better continentally ranking among the top 10 in most years under review while UJS was in the hundreds. Globally UJS outshone UON bringing out a stronger review of not just UJS but Asian HEIs in comparison their African counterparts. both THE and WRWU had a better qualitative assessment in comparison to WRWU's quantitative outlook with five and four incomparable variables respectively.

For each indicator, the highest scoring institution is assigned a score of 100 , and other institutions are calculated as a percentage of the top score. Standard statistical techniques are used to adjust the indicators if necessary. Scores for each indicator are weighted according to percentages above indicated to arrive at a final overall score for each institution. The highest scoring institution is assigned a score of 100 , and other institutions are calculated as a percentage of the top score.

Aspects such as; collaboration, internationalization of faculty and the student body draws conclusive thrusts to the institutions under review by placing them higher in the ranking scale. This is a benchmark for HEIs seeing to join the scale in global ranking as analyzed by Dill, Merisotis and Salmi in ranking and academic quality assessment [4-6].

\section{Result Research Innovation}

An aggregated research design utilizing both qualitative and quantitative techniques is implored.

The quantitative design is as a concern of third and fourth objective expected to find out the comparative significance, directions and correlational characteristics amid UJS \& UON's contemporary higher education characteristic variances in their process of academic growth and development as they strive to better their higher education's quality. It employs two different sets of primary data relevant to key questions regarding the quality of academics and HEIs academic department, and an assortment of econometric techniques and methodologies best fitting the aim, and the data generating process as analyzed by Calitz in A Ranking Framework for Higher Education Institutions pp. 40-61 [7]. Part of relevant econometric techniques implied include; the analysis of Variance and Correlation methods, the Structural Regression Model (SEM), Ordinal regressions, and Paired samples and or independent sample T-tests to best delineate the inter-temporal relations and effects of and/or academic quality and its key parameters.

The qualitative design by the study for the first two aims of study is based on qualitative review of relevant ranking literature drawing from ranking systems with approaches based on the following key areas;

The driving force behind inception of Global Higher Education Ranking (GHER) and how have the agencies involved in Higher education ranking amid incumbent constraints concerning ranking of Higher Education and the ways through which Jiangsu university collaborates with the highest ranked higher institution of education a midst striving to improve its own 69+-ranking.

Specifically, the design is comprising of some well-known literature based, and experimented systems of ranking as;

\section{Discussion Comparative Ranking}

Largely, there are still disagreements among the authors of these indicators as to what indicates quality. The world's main ranking systems bear little if any relationship to one another $[8]^{4}$, using very different indicators and weightings to arrive at a measure of quality [19].

Usher and Savino [19] discusses 4 sets of league tables from around the world where they update their ranking results by recording changes in methodology in a few of these rankings, as well as providing data on THE and

\footnotetext{
${ }^{4}$ Camilleri, M. A. (2021b). Using the balanced scorecard as a performance management tool in higher education. Management in Education, 35 (1), 10-21.
} 
WRWU as new systems of Global rankings according to Trinidad, toward greater access and impact pp 201-210, Trinidad, More than professional skills: student perspectives on higher education's purpose. $p p$ 1-15, and Trostyanskaya, The impact of changes in the world ranking methodologies on university positions. $p p$ 71-79 [9-11] Specifically, the researcher compares these league tables in terms of their methods of data collection and their selection and weighting of indicators, and also look at Jiangsu University as a HEI. Additionally, they seek to address why the Gap still exists despite its conglomeration and diversity in academic disciplines, and the high percentage of increasing international recognition portrayed through high and growing students' intake.

Based on the aims of this paper, a qualitative review of the underlying antecedent-development literature concerning the ranking systems of higher academia is closely executed, and the outcome analyzed to identify the nature of the underlying and the emerging ranking systems in an effort to understand the development dynamics of education quality amid UON and UJS.

In contrast to this approach, other researchers have shown that one of the main causes of institutional unease is the tendency of institutional ranking schemes to use weighted aggregates of indicators to arrive at a single, all-encompassing quality 'score', which in turn would permits institutions to be ranked against one another (as in table 1). By selecting a particular set of indicators and assigning each a given weight. By this, the authors of these rankings are imposing a specific definition of quality on the institutions being ranked. Though Jiangsu University may meet some indicators set, it may be unable to convincingly close the Gap of disparities based on the variables set by strictly adhering with this technique of ranking.

To this end, a quantitative technique is implored and which presumably implores a contingent of weights courtesy of statistical tools to result to (though weighted) outcomes but consistent and robust for leading conclusions.

\subsection{Ranking Approach}

The adaptable ranking systems provides a single integrated score while allowing ordinal ranking of entire institutions. However, this may ineptly place a university ranking especially for case where no intrinsic reason why indicators must focus solely on institutions. Such approaches look at institutions departments or faculties at administrative levels.

One such system is the self-aggregated ranking which provide comprehensive departmental level rankings across entire universities as analyzed be Cave, M [12]. They provide separate rankings for each discipline. Sub-institutional rankings such as; the field of study level have no weights attached. Giving no indicators and weights scores and not aggregating to create an overall 'score', meaning that no institution is declared 'best', rather, results are posted online and users of the rankings create their own rankings by selecting the indicators which are of interest to them and then receiving personalized result summaries based on their choices

\subsection{Data Sources}

The key sources of data for current study involves University sources. The most complete and most detailed sources of data on universities are of course universities themselves, and they are thus potentially a very rich source of data.

Surveys of the opinions or experiences of various stakeholders can be used to obtain comparable data on different institutions regarding educational quality as reviewed be Clerk, M. [13]. The use of each source of data has strengths and weaknesses.

Independent third-party administrative data (usually from governments or grant-making bodies) is at least theoretically, both accurate and impartial. The problem is that this data is not collected for the purpose of ranking but as an administrative institutional requirement as Usher, A., \& Savino, in A World of Difference, pp 67-70 reviews it [14]. As a result, over-reliance on this source of data can lead to a situation where indicators are chosen simply on the basis available data rather than because they contribute to a sensible definition of quality. Certainly, there are few if any measures from these sources, which can provide much insight into the actual learning environments or even in many instances' student outcomes from individual institutions. This is according to Ubaka, et al in-Webometrics ranking: a less commercialised (and more objective) measure of ranking for institutions of higher learning. $P g$ 169-184, [15].

However, many rankings systems perhaps most notably U.S. News has taken the trouble of asking institutions to provide information about themselves for the rankings. The benefit of this approach is that, this in theory answered a number of questions about institutional quality and learning environments that could not otherwise have been answered.

Through government statistics, one can know what the teacher to pupil ratio at a school is, but one would not know things like average class sizes or the number of classes where professors or graduate students are teaching first year classes unless one asked institution to provide the data themselves as modeled by Chowdhury on Global Ranking framework \& Indicators of Higher Educational Institutions: A Comparative Study Pp 56-63 [16]. The main drawback is that there was absolutely no guarantee that institutions will actually report the data to the ranker on a consistent basis, as all have a clear incentive to manipulate data in a manner, which will benefit them as researched by Henry, et al in Factors Contributing towards Research Productivity in Higher Education pp 203-211 and Holstein et al in Strategy and narrative in higher education. $P p$ 61-91. [17, 18] Indeed, at some institutions, there are staff positions within institutional research offices, which require the incumbent to do nothing but provide institutional data to the ranking systems. And, of course, over reliance on institutional data sources leaves one vulnerable to institutional manipulation.

Finally, there is survey data, which is used to get the opinions of 'experts' usually professors, administrators and employers 
about the quality and reputation of various institutions. This data is scientific in the sense that it records observations accurately, but has been criticized for being misused or acting as a 'lagging indicator' of school quality. However, as has shown, narrowly focused reputation surveys can actually be very useful, as professor's views about relative departmental quality is actually an extremely good proxy for research output. More recently, surveys of students have become an important source of data in rankings, notably in the German CHE, Canadian University Navigator and the two Dutch rankings. The increasing use of this type of data is creating a real shift in the kinds of topics which rankings are being used to assess.

ARWU solved this problem by relying almost exclusively on research output measures such as scientific publications and citations. In the cases of the US News and World Report, Maclean's, the Guardian and Rzeczpospolita, the explanation seems to be that the editors' definitions of 'quality' could not be measured using government administrative data. This may indicate a failure of government data collection in these countries, in the sense that information deemed important to quality measurement is not collected on a consistent and centralized basis; alternatively, it may indicate that the rankers' views of what constitutes an indicator of quality is not shared by governments or the higher education community.

\subsection{Data Collection}

A key issue in rankings is the method used to collect data. There are basically three sources of data on institutions Independent third parties. Frequently, government agencies will collect and publish data on institutions in their jurisdiction. This is used as a standard tool to compare institutions. This data is very often used for resource allocation.

A mixed method approach is implored in relation to the data and analytics. That is, to collect the relevant data, its analysis and presentation. Subsequently, the data set is both qualitative and quantitative while befitting the main objectives of current study.

\section{Conclusion. Nature of and Parameter Variances of Ranking Systems}

Primarily, a qualitatively aligned evaluation review study first takes course to objectively identify and distinguish among key ranking systems of higher education; that is, their nature by which they rank the HEIs while concurrently gearing to explicitly determine the parameter variances the ranking systems implore to calibrate developmental antecedents of higher academia. Additionally, a case study done is for finding out the quality of and development antecedents of the HEIs in their natural setting and purposefully to yield in-depth data from numerous sources. Tied to this, the said is a reflection of the techniques best aligning to the first and second objective of current study.

HEIs Comparability: UON and UJS academic quality

Still, quantitative data regarding the ranking systems but concerning the growth antecedents of HEIs, is critical to quantify the quality of higher academia [19]. Largely, this is a reflection and concern of the third objective which aims to compare the academic quality amid UON and UJS. For this case a questionnaire is the main tool implicated to collect data implored to quantify ranking of these HEIs. A point to note is that the questionnaire is designed using parameters identified in the ranking systems in section 3.1.

Thus, methodological concern by this third objective generally entangles a case study carried over the period March to June 2020 for the target population being the students of both UON and UJS undertaking their undergraduate and post-graduate studies. A questionnaire in both open ended for qualitative and closed-ended for quantitative data collection is adopted.

Further, reflection of expected target population presumably has a close to and/or greater than $10^{3}$ people and implying the significance of the Fisher (1983) formulae in concluding the expected sampling total and the expected sampling procedure that would minimise sampling bias. Thus, if $(n)$ is the sampling size, Fisher accords the sampling size to be given as;

$$
n=\frac{z^{2} p q}{e^{2}}=\frac{1.96^{2}(0.5 \times 0.5)}{0.05^{2}}
$$

Where $Z$ is the $95 \%$ confidence interval, $e$ - sampling error, $p$ - maximum population variability at $5 \%$ and $q=$ (1- $p$ )- the sapling probability as the Fisher sample totals to 384. But due inevitable survey-response error and discrepancies, current study targeted 500 respondents after which fully filled 384 questionnaires will be banked on.

a) The Questionnaire

The tool highly regarded for the third objective in which a comparative analogy of the academic quality of UON and UJS is to be demonstrated to identify their antecedent growth gap. In regard, a questionnaire constituted implicating the academic quality is fabricated using some known parameters of ranking. That is, some parameter determinants adopted by the ranking systems such as teaching, attitude, internationalization, research and performance are implored by current study. Their effect will be observed on the endogenous variable which constitutes "ranking reliability" variable. For precision, the exogenous is a set constructed from their respective determinants. In both HEIs, the variables; teaching, attitude, performance, internationalization and research cuts across the academic circles.

To start with, teaching is parametrized by university reputation, curriculum quality, staff qualification and the student-teacher ratio but taking the four questions; (i) how the learner finds reputation punctuation of university of study, (ii) effectivity/inclusivity and quality of curriculum offered at university of study, (iii) the qualification level of teaching staff, and the (iv) student to teacher ratio for efficiency of teaching and resources provision. By learner's attitude, the questionnaire parameterized this via investigation to know 
learner's attitude towards (i) teaching staff and (ii) curriculum satisfaction. With research variable, it was explored using the inquisitive; (i) whether the institution of study receives academic research grants and its sufficiency level (ii) extent academic supervisors encourage and require peer reviewed journals citation and publication, (iii) whether or not university of study conducts reputation survey for research before assigning research direction for its students, (iv) autonomy and sufficiency level of the student in selecting own research directions, and (v) whether or not research output and publications in (Natural sciences//PU'SCI SSC) is conditional requirement to graduate. Regarding internationalization variable, the study sough to find out; (i) satisfaction level of the university of studies' university's academic/research reputation, (ii) whether or not the institutional reputation was a determinant of the students' choice of study and level this influenced the choice, (iii) the percentage/ratio of domestic to international student, (iv) whether or not for the university of study, a member in past or present is/has been a Nobel prize winner, (v) the preference level to students of Nobel prize compared to those without a Nobel price, and the (vi) extent of alumni employability. For performance, its investigated by the inquisitive; (i) the sufficiency level of the education quality in meeting the students socio-economic/academic needs, (ii) whether or not the university of study engage in activities to improve its income on its per capita performance and (iii) degree of agreement with the fact that the institutions of study income/research transformation significantly affect the countries general economy. The endogenous variable as the ranking quality is also on a five-point Likert-question expecting to find out the students' insight level of the reliability of the raking systems.

The variables are calibrated based on the five-point Likert-type scale 1 to 5 of either design as strongly disagree/very low to strongly agree/very high or based on the binary format (1-yes/positive; 0-otherwise) for the based question.

The study via one of the aims expects to empirically analyze the effect of teaching, internationalization, research, performance and attitude to ranking reliability and the correlations amid the dependent and independent variables. The exercise will encompass some guided regression based on distribution of the sample data.

b) Variable operationalization

Basically, the third objective is key in demonstrating the comparative analogy of the academic quality amidst UON and UJS in order to address their academic disparity and or growth/ developmental variances. Thus, variable operationalization expects to initiate with the transformation of the data and imploring their distribution. Initially some descriptive of relevant constructed variables of ranking quality and systems of HEIs is implored on the data followed by relevant data diagnostics to determine its behavioral distribution. This way is necessary precondition for identifying the correct method of data analyses and which would be analogous to said objective. In line, inferential analytics for operationalization have been succinctly selected based on behavioral postulations of the dataset. The ordinal regressions, analysis of variance, independent T-test along other statistical analytics have been key in operationalization. Comparative dimensions explored include correlations, variabilities and impact of the departmental variables on the academic quality and or reliability.

\section{References}

[1] Altbach, P. G. (2012). The globalization of college and university rankings. Change: The Magazine of Higher Learning, 44 (1), 26-31.

[2] Calitz, A. P., Cullen, M. D., \& Kanyutu, T. W. (2021). A Ranking Framework for Higher Education Institutions: A Students' Perspective University-Industry Collaboration Strategies in the Digital Era (pp. 40-61): IGI Global.

[3] Camilleri, M. A. (2021b). Using the balanced scorecard as a performance management tool in higher education. Management in Education, 35 (1), 10-21.

[4] Cave, M. et al. 1997. The Use of Performance Indicators in Higher Education. The Challenge of the Quality Movement. 3rd edition. London: Jessica Kingsley Publishers.

[5] Chowdhury, A. R. (2021). Global Ranking framework \& Indicators of Higher Educational Institutions: A Comparative Study.

[6] Clarke, M. 2002. "Some Guidelines for Academic Quality Rankings". Higher Education in Europe (27), 443-459.

[7] Dill, D. D. and Soo, M. 2004. Is There a Global Definition of Academic Quality? A Cross-National Analysis of University Ranking Systems. Chapel Hill, NC: Public Policy for Academic Quality Background Paper, University of North Carolina.

[8] Henry, C., Ghani, N. A. M., Hamid, U. M. A., \& Bakar, A. N. (2020). Factors Contributing towards Research Productivity in Higher Education. International Journal of Evaluation and Research in Education, 9 (1), 203-211.

[9] Holstein, J., Starkey, K., \& Wright, M. (2018). Strategy and narrative in higher education. Strategic Organization, 16 (1), $61-91$

[10] Hsieh, M. Y. (2020). The most sustainable niche principles of social media education in a higher education contracting era. Sustainability, 12 (1), 399.

[11] Merisotis, J. 2002. "On the Ranking of Higher Education Institutions". Higher Education in Europe 27 (4), 361-363.

[12] Salmi, J. 2007. Recent Developments in Rankings: Implications for Developing Countries? Presentation given at the 3rd meeting of the International Rankings Expert Group, Shanghai, October 29, 2007.

[13] THE (www.timeshighereducation.com/; QS (www.topuniversities.com; WRWU www.webometrics.info/en.

[14] Tosun, H. (2019). A Performance Assessment Model Recommended for Higher Education System in Turkey and a Case Study. Psychology Research, October, 9 (10), 420-431. 
[15] Trinidad, J. E., \& Leviste, E. N. P. (2021). Toward greater access and impact: Directions for a sociological understanding of Philippine higher education. Industry and Higher Education, 35 (3), 201-210.

[16] Trinidad, J. E., Raz, M. D., \& Magsalin, I. M. (2021). "More than professional skills:" student perspectives on higher education's purpose. Teaching in Higher Education, 1-15.

[17] Trostyanskaya, I. B., \& Polikhina, N. A. (2018). The impact of changes in the world ranking methodologies on university positions. Sotsiologicheskie issledovaniya (9), 71-79.
[18] Ubaka, A. U., Baharudin, K., \& Sentosa, I. (2018). Webometrics ranking: a less commercialised (and more objective) measure of ranking for institutions of higher learning. International Journal of Continuing Engineering Education and Life Long Learning, 28 (2), 169-184.

[19] Usher, A., \& Savino, M. (2006). A World of Difference: A Global Survey of University League Tables. Canadian Education Report Series. Online Submission. 67-70. 